\title{
Changing Pattern of Shingles (Herpes Zoster) in Hill Tracts: A Study among Tribal Community of Bangladesh
}

\author{
Ahmed Tanjimul Islam ${ }^{1}$
}

\begin{abstract}
Background: Herpes zoster infection (shingles) is a common painful disease in Bangladesh. Changing pattern of the disease presentation can cause delayed diagnosis, inappropriate treatment, prolongation of the disease with debilitating symptoms and post herpetic neuralgia. Objective: The study was done to evaluate the different changing clinical and dermatome pattern of shingles among tribal community in Hill tracts of Bangladesh. Materials and method: This descriptive hospital based study was carried out among 74 shingles patients using simple, direct, standardized questionnaire with history, clinical and dermatological examination from July 2015 to July 2016 in Rangamati General Hospital, Rangamati, Bangladesh. Results: August to October was the vulnerable period for Shingles (75.7\%) with highest number of cases found in September (32.4\%). Rural area (70.2\%) is vulnerable than urban area. Lumbar region (39.1\%) is the commonest dermatome involved during examination. Itching was the commonest complaint (41.9\%) for physician consultation and $15 \%$ cases suffered reactivation within six months in the same dermatome region. Conclusion: As changing and different pattern of manifestations are common in shingles in Hill Tracts, these are to be considered by local and consultant physicians in the total management to decrease delayed complications and reactivation.
\end{abstract}

Key words: Shingles; changing pattern; Hill tracts.

Delta Med Col J. Jul 2019;7(2):56-60

\section{Introduction}

Herpes zoster (HZ), commonly known as shingles, is a dermatological disease diagnosed clinically by vesicular eruption with radicular pain that is generally limited to the unilateral dermatome supplied by a single cranial or spinal sensory ganglion. The skin lesions are characterized by erythematous grouped vesicles without any secretion. It occurs due to persisted and latent form of varicella zoster virus (VZV) that reactivated within sensory ganglion following a previous attack of zoster virus. ${ }^{1}$ Varicella-Zoster (VZV) is a human DNA virus. Zoster is found worldwide, but it is more common in temperate climates. In Asia, specifically in certain South Asian countries the overall prevalence of zoster (HZ) is relatively low. ${ }^{2}$ This combined with variable climatic conditions are causing different morphological and seasonal pattern in HZ virus manifestation. ${ }^{2,3}$ The reactivation of the herpes zoster results from decrease of specific CMI

1. Medical Officer, Rangamati General Hospital, Rangamati, Bangladesh.

Correspondence: Dr. Ahmed Tanjimul Islam. e-mail: droveesomch@gmail.com 
(cell mediated immunity), which in turn may be triggered by trauma, psychological stress, sunburn, irradiation, cytotoxic chemotherapeutic drugs and age. ${ }^{3}$ The clinical expression of the disease from mild to disseminated form is related to the rapidity of immune response that is variable in different people. Thoracic and cervical are the commonest dermatome to be involved. ${ }^{4}$

In Hill Tracts, due to high altitude and immunity variation, there is a different pattern of seasonal peak, demographic features and dermatome affection which is not similar to other non-hilly regions. To our best knowledge, there is no previous hospital-based study on seasonal, demographical and dermatome distribution pattern of Herpes zoster (HZ) in Hill Tracts among tribal community. So, this study was done to find out the different pattern of presentation of shingles among tribal community in Hill Tracts of Bangladesh.

\section{Materials and method}

This was a descriptive hospital based observational study, based on the interview and clinical examination of the patients presented with the shingles (Herpes zoster) in Rangamati General Hospital, Rangamati, Bangladesh. The aim of this study was to evaluate the seasonal, demographic, clinical and dermatological distribution of shingles. Patients were followed up for 6 months to detect any reactivation.

The study population included all those tribal patients who came to hospital outdoor or were admitted as shingles cases at Rangamati General Hospital, Rangamati, Bangladesh during twelve months period (July 2015 to July 2016). Patients with only obvious clinical diagnosis were included for the study. Clinical criteria which we considered as shingles were any person having abnormal skin sensations with an acute onset of localized macular, popular or vesicular unilateral rash, involving at least one dermatome.

A full detailed history and proper systemic and dermatological evaluation was performed by the author with consultant physicians and dermatologist. Data were collected, tabulated and statistical analysis was performed using software SPSS version 16.

\section{Ethical considerations}

Informed written consent was obtained from all the participants. Ethical clearance was obtained from Chittagong Medical College Hospital ethical committee (CMCH: Ref: 149/009/2015).

\section{Results}

Total patients presented as definite clinical diagnosis of shingles was 74 within our study period (one year). All were diagnosed in both outpatient and indoor department. We studied for seasonal variation of shingles cases. Most of the cases presented between August to October (75.7\%) with highest cases recorded in September $(32.4 \%)$. Very few cases were found in rest of the year (less than 5 cases in each month). (Fig 1)

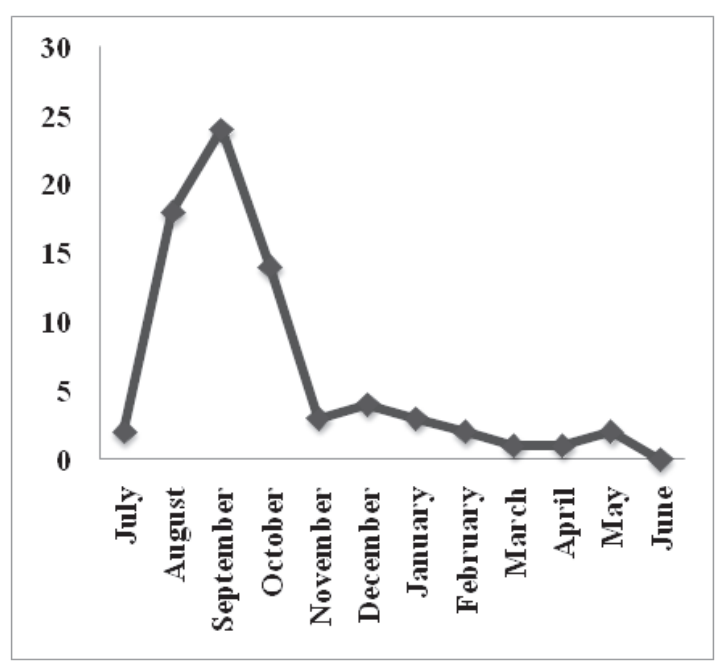

Fig 1: Seasonal distribution of Herpes zoster

We also assessed for demographic distribution of shingles. Majority cases were from rural areas (70.2\%). Of them 3 cases were from very remote areas of Hill Tracts. Twenty two cases came from urban area (29.8\%). (Fig 2) 


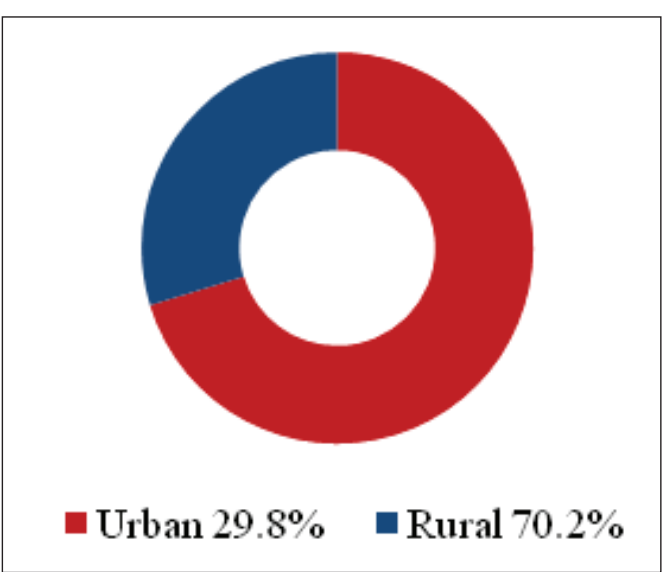

Fig 2: Demographical distribution of Herpes zoster

Regarding dermatome distribution of shingles, commonest dermatome involved was lumbar region (39.1\%). Sacral region involvement was also common $(20.2 \%), 14.8 \%$ had thoracic and $16.1 \%$ cervical region involved. Cranial nerve was involved in 6 cases $(8.1 \%)$ whereas 3 patients presented with facial nerve palsy. (Table I)

\begin{tabular}{lcc}
$\begin{array}{l}\text { Table I: Dermatome / } \\
\text { distribution of Herpes zoster }\end{array}$ & \\
\multicolumn{1}{l}{ Cranial } & nerve \\
\hline Dermatome/ Cranial nerve & Number of patients (n) & Percentage \% \\
\hline V1 & 1 & 1.5 \\
V2, V3 & 2 & 2.6 \\
VII & 3 & 4.1 \\
Cervical & 12 & 16.1 \\
Thoracic & 11 & 14.8 \\
Lumbar & 29 & 39.1 \\
Sacral & 15 & 20.2 \\
Disseminated & 1 & 1.6
\end{tabular}

Analysis of the chief complaints of patients reveals itching as the commonest complaint for hospital arrival (41.9\%) and 18 patients complained of pain $(24.3 \%)$. The pain was of non specific type and mild to moderate in severity with no specific pattern. Burning sensation (17.5\%), severe discomfort $(8.1 \%)$, fever $(4 \%)$, headache $(2.7 \%)$ and weakness (1.4\%) were also complained by the shingles patients. (Fig 3 )

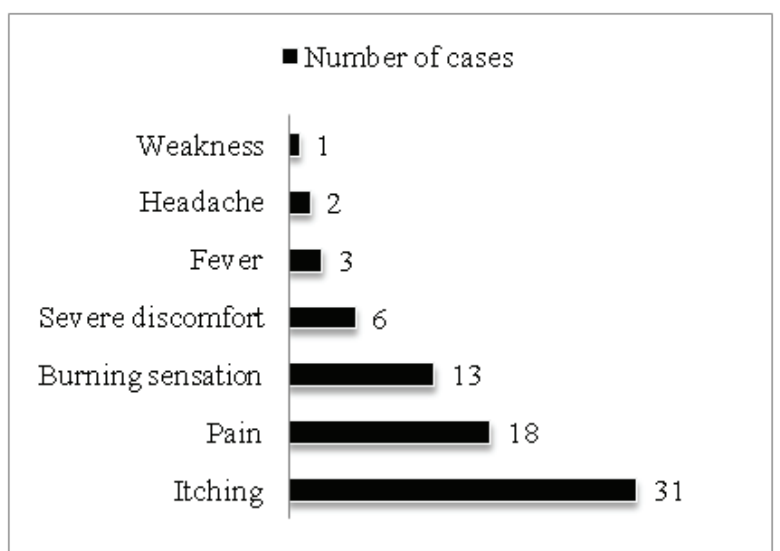

\section{Fig 3: Chief complaints of Herpes zoster}

The patients were followed up for six months to detect any reactivation of shingles. All patients received antiviral and symptomatic treatment as initial management. Only 11 patients (15\%) returned with reactivation of shingles with similar dermatome distribution. Each patient had complaints similar to previous one. (Fig 4)

- Reactivated (15\%) $\quad$ No Reactivation (85\%)

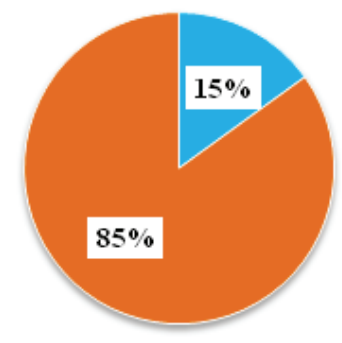

Fig 4: Reactivation within six months on follow up

\section{Discussion}

We have assessed for seasonal, demographic and dermatologic manifestation of shingles (Herpes zoster) among patients in Hill Tracts of Bangladesh. Assessment was done by the author and consultant dermatologist following clinical guidelines. According to the study findings, most of the shingles cases were observed between the month of August and November with highest number of cases in September. The prevalence was more common in remote rural area than urban 
areas in Hill Tracts. This study also reveals that lumbar region is the commonest dermatome to be involved. Itching is the commonest complaint by the patients and there is $15 \%$ reactivation of the cases within six months.

This study reveals August to November as a vulnerable period for shingles in Hill Tracts. Probably this is due to seasonal variation with higher temperature continuing till November in Hilly areas of Bangladesh. Previous study done in 2011 in Pakistan showed April to July is the vulnerable season for shingles which is dissimilar to our study. ${ }^{5}$ Studies done in Sri Lanka and India for seasonal variation of shingles were also not similar to our study. 6,7

Our study also revealed itching as the commonest chief complaint. Previous research done in Japan showed pain as the commonest symptom ${ }^{8}$, while two researches done in India in the year 2011 and 2004 found weakness as commonest complaint which were not similar to our study. ${ }^{9,10}$

We found that lumbar region is the commonest dermatome to manifest shingles. Reactivation is also common in lumbar dermatome. A study done in Singapore showed thoracic region is the commonest dermatome to be involved. ${ }^{11}$ Studies done in different countries also showed almost similar observation. ${ }^{12,13}$

In our study $15 \%$ subjects reported reactivation within six months. This is probably due to immune suppression, unhygienic condition and malnutrition status of tribe community. Similar results were observed in previous studies done in Nepal and India. ${ }^{14,15}$

To the best of our knowledge, different seasonal variation and changing dermatome pattern of Herpes zoster and reactivation status is assessed for the first time among tribal community in Hill Tracts of Bangladesh. Shingles in Hill Tracts is determined for the first time by our study.

\section{Conclusion}

Early evaluation of shingles will improve the diagnostic accuracy and treatment outcome in Hill
Tracts. This can ameliorate the prognosis in shingles. Primary care doctors and consultants need to develop systematic strategies to screen for different pattern of presentation to decrease the reactivation and long term complication.

\section{Limitations}

As no microscopic and histological confirmation was possible in Hill Tracts, doubtful cases of shingles were excluded from the study.

\section{References}

1. Wood MJ. History of Varicella Zoster Virus. Herpes. 2000;7:60-65.

2. Gnann JW, Whitley RJ. Herpes Zoster. N Engl J Med. 2002;347:340-46.

3. Arvin AM. Varicella-Zoster Virus. In: Fields BB, editor. Virology. 3rd ed. New York: Raven Press; 1995. p. 2547-86.

4. Cohen JI, Brunell PA, Straus SE, Krause PR. Recent Advances in Varicella-Zoster Virus Infection. Ann Intern Med. 1999;30:922-32.

5. Suhail M, Ejaz A, Abbas M, Naz S, Suhail T. Herpes Zoster: Seasonal Variations and Morphological Patterns in Pakistan. J Pak Asso of Dermatol. 2011;21;22-26.

6. Liyanage NP, Fernando S, Malavige GN, Mallikahewa R, Sivayogan S, Jiffry MT, et al. Seroprevalence of Varicella-Zoster Virus Infections in Colombo District, Sri Lanka. Indian J Med Sci. 2007;61:128-34.

7. Dubey AK, Jaisankar TJ, Thappa DM. Clinical and Morphological Characteristics of Herpes Zoster in South India. Indian J Dermatol. 2005;50:203-207.

8. Toyama N, Shiraki K. Epidemiology of Herpes Zoster and Its Relationship to Varicella in Japan. J Med Virol. 2009;81:2053-58.

9. Abdul Latheef EN, Pavithran K. Herpes Zoster. A Clinical Study in 205 Patients. Indian J Dermatol. 2011;56:529-32.

10. Laxmisha C, Thappa DM, Jaisanker TJ. The Spectrum of Varicella-Zoster Virus Infection: A Hospital-Based Clinic in South India. Indian J Dermatol. 2004;49:28-31. 
11. Goh CL, Khoo L. A Retrospective Study of the Clinical Presentation and Outcome of Herpes Zoster in a Tertiary Dermatology Outpatient Referral Clinic. Int J Dermatol. 1997;36:667-72.

12. Chaudhary SD, Pahwa DA. A Clinico-Epidemiologic Profile of Herpes Zoster in North India. Int J Dermatol Venereol Leprol. 1987;53:213-16.

13. Choo PW, Donahue JG, Manson JE, Platt R. The
Epidemiology of Varicella and Its Complications. J Infect Dis. 1995;172:706-12.

14. Kayastha BMM, Shrestha P, Shrestha R, Lama L. Changing Profile of Herpes Zoster in Nepal: A Hospital-Based Study. Nepal Journal of Dermatology, Venereology \& Leprology. 2009;8:1-4

15. Talwar S. Herpes Zoster Associated with Varicelli form Eruption. Indian J Dermatol Venereol Leprol. 1991;57:52-57. 